\title{
A CAPACITAÇÃO DE PROFESSORES A DISTÂNCIA, UM MODELO DE SALA DE AULA INVERTIDA USANDO AMBIENTE VIRTUAL DE APRENDIZAGEM E REUNIÃO ON-LINE.
}

\author{
SÃO PAULO/SP AGOSTO/2018
}

\author{
Rita de Cassia Carolino - UNIITALO - rcarolino@hotmail.com \\ Ana Cristina das Neves - UNIITALO - ana.neves@italo.br
}

Tipo: Relato de Experiência Inovadora (EI)

Categoria: Métodos e Tecnologias

Setor Educacional: EDUCAÇÃO CONTINUADA EM GERAL

\begin{abstract}
RESUMO
O presente trabalho visa descrever um dos processos de capacitação docente realizado pela Academia de Educadores do Centro Universitário Ítalo Brasileiro. A pesquisa versa sobre o desenvolvimento da aprendizagem permanente do professor, via Ambiente Virtual de Aprendizagem, sobretudo considerando as práticas de metodologias ativas.

Para tanto, baseamos nossa pesquisa nos estudos de formação continuada de Perrenoud (2001); aula invertida de Bergman e Sams (2012) e Pierce e Fox (2014). Consolidando o presente estudo, nos valemos ainda de fundamentos da educação com base em Freire (1997) e Pimenta (2010) e a virtualidade é representada pelos estudos de Levy (1999). A explanação do Ambiente virtual de aprendizagem é sustentada pelas pesquisas de Bates (2016) e Maciel (2012). Em todos os aspectos preconizando sempre os referenciais estabelecidos pelo MEC.

Assim, este artigo é o resultado de um trabalho iniciado em fevereiro de 2018, cujo o objetivo é a formação contínua dos docentes que estão fisicamente separados da instituição, porém devem representá-la nos Estados em que atuam e, desta forma, atingir não somente a capacitação integral, mas a redução de custos com passagens e hospedagens e a disseminação da metodologia de ensino da Instituição.

As etapas já concluídas demonstraram a eficiência da formação dos docentes por meio das práticas de sala de aula invertida e discussões estabelecidas, seja via vídeo conferência, seja via fóruns no ambiente virtual. Tais resultados foram medidos por meio de análises das práticas pedagógicas desenvolvidas, ao longo do semestre, pelos docentes capacitados e, documentalmente, pelas avaliações aplicadas e pelos planos de ensino analisados pela Academia de Educadores do Centro Universitário Ítalo Brasileiro - São Paulo.
\end{abstract}

Palavras-chave: formação, capacitação, flipped class-room, sala de aula invertida 


\section{Introdução}

O presente artigo traz o relato de uma experiência realizada no Centro Universitário Ítalo Brasileiro em São Paulo. A Instituição promoveu capacitação para os professores dos polos educacionais, visando transmitir as orientações relacionadas às práticas de trabalho e cultura organizacional na resolução de questões educacionais.

A primeira etapa da capacitação ocorreu entre fevereiro e maio, e teve como objetivo principal levar os professores ao entendimento das questões práticas de atuação como uso do sistema acadêmico e ambiente virtual e mais especificamente sobre as praticas das metodologias ativas: sala de aula invertida, instrução entre pares, aprendizado baseado em problemas e aprendizagem baseada em projetos. As próximas etapas visam à mentoria, que é quando um professor acompanha a execução dos outros professores e orienta como alinhar a metodologia ao plano de ensino.

Para contextualização do relato de experiência, é abordado de maneira didática, neste artigo, a importância e linha de pesquisa relacionada à capacitação docente; a metodologia e teoria aplicada com a sala de aula invertida; posteriormente é relatada a pesquisa sobre o ambiente virtual de aprendizagem e sua relevância quando abordamos a capacitação na modalidade a distância, utilizando o paralelo com a Educação a Distância. Logo em seguida deixa-se claro ao leitor a metodologia utilizada e por fim as discussões necessárias a partir do relato da experiência vivida neste período, além de apresentar os planejamentos e as expectativas em relação às novas fases propostas para esta capacitação.

\section{Capacitação Docente}

A formação de professores vem assumindo posição de urgência (PERRENOUD, 2001) nos espaços escolares e, a formação continuada associa-se ao processo de melhoria das práticas pedagógicas desenvolvidas pelos professores em sua rotina de trabalho e em seu cotidiano escolar. A formação relaciona-se também à ideia de aprendizagem constante no sentido de provocar inovação na construção de novos conhecimentos que darão suporte teórico ao trabalho docente.

O docente é um profissional que deve dominar a arte de despertar nas pessoas a capacidade de engajar-se e isso se torna cada vez mais difícil quando nos deparamos com alunos que entram em sala de aula com celulares conectados a internet, ou seja, mergulhados num ciberespaço (Levy, 1999) com assuntos e demandas mais interessantes que a aula que o docente pretende proferir. 
Neste aspecto, entende-se que a formação do professor é indispensável para a prática educativa, a qual se constitui o lócus de sua profissionalização cotidiana no cenário escolar. Desse modo, compreender a formação docente incide na reflexão fundamental de que ser professor é ser um profissional da educação que trabalha com pessoas. Essa percepção induz este profissional de educação a um processo permanente de formação, na busca constante do conhecimento por meio dos processos que dão suporte à sua prática pedagógica e social. Neste sentido, a educação é um processo de humanização e, como afirma Pimenta (2010), é um processo pelo qual os seres humanos são inseridos na sociedade. Aqui, cabe lembrar Freire (1997) ao expressar que o ensinar não se limita apenas em transferir conhecimentos, senão também no desenvolvimento da consciência de um ser humano inacabado em que o ensinar se torna um compreender a educação como uma forma de intervir na realidade da pessoa e do mundo. E ainda de acordo com Demo (2000), a pedra de toque da qualidade educativa é o professor visto como alguém que aprende a aprender, alguém que pensa, forma-se e informa-se, na perspectiva da transformação do contexto em que atua como profissional da educação.

\section{Sala de Aula Invertida}

A aula invertida é uma abordagem híbrida de ensino descrita pelo educador americano Salman Khan e desenvolvida por Jonathan Bergmann e Aron Sams, em 2007, para resolver o problema de estudantes do ensino médio que estavam ausentes nas aulas presenciais e perdiam, portanto, o conteúdo apresentado pelo professor (BERGMAN; SAMS, 2012a; PIERCE; FOX, 2014). No modelo da aula invertida, as instruções dos conteúdos se realizam fora da sala de aula por meio de videoaulas, leituras e outras mídias, sendo o tempo de sala de aula liberado para realização de atividades ativas, nas quais os alunos praticam e desenvolvem o que aprenderam com o auxílio e supervisão do professor (DATIG; RUSWICK, 2013).

Neste modelo de aprendizagem, o professor continua sendo o principal responsável por guiar os estudantes sobre como compreender e aplicar as novas informações, principalmente àquelas recém adquiridas, necessitando utilizar uma abordagem de interação diferente da utilizada no ensino tradicional.

\section{Ambiente Virtual de Aprendizagem}

O Ambiente Virtual de Aprendizagem, doravante AVA, pode ser definido como um cenário programado para apresentar contextos de aprendizagem. Nele são disponibilizados os materiais de leitura, as propostas de atividades, os vídeos e demais 
materiais de aulas em EaD. Também são promovidas as trocas de saber e a interatividade entre os atores envolvidos neste processo de ensino e aprendizagem, os quais via de regra são: estudantes, tutores e professores da modalidade a distância e, em nossa pesquisa professores capacitadores e professores capacitados. (BATES, 2016).

As atividades previstas em um AVA podem ser síncronas e assíncronas, estas se dão em tempo distinto entre os envolvidos, aquelas são simultâneas, a interação ocorre instantaneamente, ou seja, ao mesmo tempo. Dentre estas atividades síncronas e assíncronas, é notadamente muito utilizada na modalidade a distância, as salas de conferências, atividade síncrona, promotora tanto de exposição de ideias, como, principalmente, de discussão de ideias e trocas de conhecimento a respeito de um tema proposto. (MACIEL, 2012).

Esta ferramenta - conferência - é utilizada para promover a troca de informações entre os participantes de determinado curso, disciplina ou capacitação, sempre com temas específicos. A proposta para o debate de ideias de forma colaborativa pode ser avaliativa ou não-avaliativa e, em nossa experiência com os professores dos Polos tornou-se fundamental na capacitação proposta, já que a ideia primordial é transmitir a cultura organizacional da sede e a temática de trabalho.

Conforme referencial de qualidade do Ministério da Educação (MEC), os cursos de educação a distância podem apresentar diferentes desenhos e múltiplas combinações de linguagens e recursos educacionais e tecnológicos. A natureza do curso e as reais condições do cotidiano e necessidades dos estudantes são os elementos que irão definir a melhor tecnologia e metodologia a ser utilizada. Tomando por base esta mesma premissa da EaD, importa-nos perceber como ocorreu a interatividade para este público tão específico: professores de graduação na capacitação promovida.

A interatividade presente de forma tão espontânea quando estamos presencialmente com os envolvidos é almejada quando estamos a distância e uma das ferramentas utilizadas para promoção do conhecimento e da interatividade são as reuniões de conferência: ferramenta possível de ser disponibilizada no AVA e que é utilizada para promover o debate a respeito de determinado assunto para troca de informações e mensagens com pontos de vistas diferentes e cujo propósito é também desenvolver a aprendizagem, o conhecimento a respeito do tema proposto.

$\mathrm{Na}$ atualidade, as pessoas estão imersas em tecnologia, novas gerações se desenvolvem em meio a smartphones, videogames, redes sociais, e até a aprendizagem 
se dá de maneira mais espontânea do que formal. Porém, mesmo com toda esta transformação, ainda é difícil encontrar pessoas que não se considerem potencialmente distantes de compreender um texto verbal, por isso a importância de utilizar o ambiente virtual de aprendizagem também como facilitador da metodologia de aula invertida.

As orientações precisam estar claras e seguir uma ordem de direcionamento ao professor para que nos momentos de reunião e interatividade todos estejam cientes sobre a temática, ou seja, a sala de aula invertida deve ser promovida de forma assíncrona para que a proposta síncrona tenha seus objetivos alcançados - debate e entendimento dos contextos propostos.

Sem dúvida, o AVA tem papel importante na efetividade das propostas, pois precisa ser um ambiente o mais amigável possível, ser facilitador para a construção de informações e também para a utilização do usuário. Aproveitar estes ambientes e apresentar novas formas do conceito de aprender, como games, filmes, revistas devem ser utilizados para aumentar a motivação e promover aprendizagem, assim é possível desenvolver melhor a habilidade de comunicação em ambientes virtuais de aprendizagem.

Quando se fala em EaD, o ambiente virtual de aprendizagem é o principal caminho de comunicação entre os atores envolvidos, assim, é mister a descoberta de maneiras eficientes de comunicação. Muitos são os relatos, nestes ambientes virtuais, de incompreensão das informações e, mais do que isto, os resultados da transmissão de informações efetuadas nem sempre são os esperados por aquele que as emitiu.

Entendido isso, é importante relatar que a plataforma utilizada nesta primeira fase da capacitação atendeu de maneira satisfatória, pois neste ambiente foram disponibilizados materiais elaborados para direcionar a pesquisa, a discussão de ideias com os grupos locais, para entendimento teórico e, a partir disso, o resultado foi, também, satisfatório nas reuniões com os capacitadores da sede, refletindo de maneira excelente a sala de aula invertida.

\section{Metodologia}

O trabalho aqui descrito foi iniciado em fevereiro de 2018 quando as primeiras necessidades de formação docente foram surgindo. Da operação do ambiente virtual de aprendizagem à inserção de notas e faltas no sistema acadêmico, tudo precisava ser multiplicado com professores que se encontravam a mais de 2000 quilômetros de distância. Tais técnicas se reproduzem por meio de manuais, tutoriais, entre outros modelos já testados e aprovados. 
Mas foi quando nos demandaram a multiplicação das metodologias de ensino que tivemos que discutir e planejar. Como mudar o paradigma de ensino de um professor? Como motivar um professor a testar uma nova metodologia de aula em que ele não é o protagonista? Desenhamos o modelo de formação docente, usando sala de aula invertida e agendamos reuniões on-line mensais com os grupos de Altamira/Pará e Itabirito/Minas Gerais.

Os professores em São Paulo, postam o material na plataforma Moodle com no mínimo uma semana de antecedência e, utilizam também, o grupo de WhatsApp para incentivar os docentes dos polos a assistirem os vídeos e interagirem na plataforma.

Os professores podem estudar os materiais postados no seu próprio ritmo, interesse ou necessidade, para isso foram divididos em partes consideradas significativas.

Durante as reuniões on-line, momento considerado presencial, as discussões foram acerca dos materiais trabalhados e dúvidas sobre os conceitos e praticas apresentadas. Além disso, operações como analisar, sintetizar e resolver problemas sobre as metodologias tratadas nas aulas virtuais transforma o momento numa troca de experiências entre os docentes locais e/ou distantes.

\section{Discussão e Conclusões}

A aprendizagem invertida se constitui enquanto um modelo educacional para a academia de educadores. Considerando os referenciais teóricos mais relevantes na área, podemos identificar sua contribuição para a disseminação do conhecimento entre os docentes do Centro Universitário Ítalo Brasileiro.

O processo envolve uma ressignificação do papel do professor e do aluno, além de uma dinâmica de espaço e tempo em que trabalham e interagem.

Com base na experiência relatada, consideramos que o desenvolvimento da formação de docentes acontece de forma mais assertiva a medida que o docente se envolve no estudo, individualmente e previamente.

A implementação das metodologias ativas e seu acompanhamento a distância se tornam o próximo passo do estudo, e um desafio para os envolvidos no processo.

A revisão dos conteúdos disponibilizados, com base na receptividade dos docentes, bem como a inserção de novas estratégias como exercícios com vídeos e debates 
virtuais fazem parte da próxima etapa do trabalho e de futuros estudos.

\section{Referências}

BATES, Tony. Educar na era digital: design, ensino e aprendizagem. São Paulo: Artesanato Educacional, 2016.

BERGMANN, J. \& SAMS, A.: Flipped learning Gateway to Student Engagement, In: Learning \& Learning with Technology, May 18--23 (2014)

DEMO, P. Educação pelo avesso: assistência como direito e como problema. São Paulo: Cortez, 2000.

FREIRE, P. Pedagogia da autonomia: saberes necessários à prática educativa. 2. ed. São Paulo: Paz e Terra, 1997.

MACIEL, Cristiano (Org.) et. al. Ambientes Virtuais de Aprendizagem. Cuiabá: EduFMT, 2012.

PERRENOUD, Philippe. A ambigüidade dos saberes e da relação com o saber na profissão de professor. In: Ensinar: agir na urgência, decidir na incerteza, do mesmo autor. Porto Alegre: Artmed Ed, 2001, p. 135-193. 11

PIMENTA, S. G. Professor Reflexivo: construindo uma crítica. In Pimenta \& Ghedin (orgs.). Professor reflexivo no Brasil: gênese e crítica de um conceito. São Paulo: Cortez Ed, 2002. (1 ${ }^{\text {a }}$ edição: junho de 2002; 2ª edição: novembro de 2002).

VALENTE, J. A. Aprendizagem Ativa no Ensino Superior: a proposta da sala de aula invertida. Nied e GGTE - Unicamp \& Ced - PucSP. 2015

\section{Fontes:}

ALVES, Lucineia. Educação a distância: conceitos e história no Brasil e no mundo. Disponível em: . Acesso em: 28 mai. 2018.

DEMSKI, J. 6Expert Tips for Flipping the Classroom. Campus Technology, v. 25, n. 5, p. 32-37, 2013. Disponível em: https://campustechnology.com/articles/2013/01/23/6-expe rt-tips-for-flipping-the-classroom.aspx 
FONSECA, J.J.S. A Aprendizagem Invertida e em educação a Distância. Disponível em: http://www.abed.org.br/congresso2015/anais/pdf/BD_86.pdf

MEC. Catálogo Nacional de Cursos Superiores de Tecnologia. 2009b. Disponível em: http://catalogo.mec.gov.br/. Acesso em 29/09/2009 